Article

\title{
Seismic Failure Mechanism of Reinforced Cold-Formed Steel Shear Wall System Based on Structural Vulnerability Analysis
}

\author{
Jihong Ye *, Liqiang Jiang and Xingxing Wang \\ The Key Laboratory of Concrete and Prestressed Concrete Structures of the Ministry of Education, \\ Southeast University, Nanjing 210018, China; jlq_1992@hotmail.com (L.J.); wangxingxing1288@126.com (X.W.) \\ * Correspondence: yejihong@seu.edu.cn; Tel.: +86-25-8379-4253
}

Academic Editor: Zhong Tao

Received: 29 November 2016; Accepted: 9 February 2017; Published: 22 February 2017

\begin{abstract}
A series of structural vulnerability analyses are conducted on a reinforced cold-formed steel (RCFS) shear wall system and a traditional cold-formed steel (CFS) shear wall system subjected to earthquake hazard based on forms in order to investigate their failure mechanisms. The RCFS shear wall adopts rigid beam-column joints and continuous concrete-filled CFS tube end studs rather than coupled-C section end studs that are used in traditional CFS shear walls, to achieve the rigid connections in both beam-column joints and column bases. The results show that: the RCFS and traditional CFS shear wall systems both exhibit the maximum vulnerability index associated with the failure mode in the first story. Therefore, the first story is likely to be a weakness of the CFS shear wall system. Once the wall is damaged, the traditional CFS shear wall system would collapse because the shear wall is the only lateral-resisting component. However, the collapse resistance of the RCFS shear wall system is effectively enhanced by the second defense, which is provided by a framework integrated by rigid beam-column joints and fixed column bases. The predicted collapse mode with maximum vulnerability index that was obtained by structural vulnerability analysis agrees well with the experimental result, and the structural vulnerability method is thereby verified to be reasonable to identify the weaknesses of framed structures and predict their collapse modes. Additionally, the quantitative vulnerability index indicates that the RCFS shear wall system exhibits better robustness compared to the traditional one. Furthermore, the "strong frame weak wallboard" and the "strong column weak beam" are proposed in this study as conceptional designations for the RCFS shear wall systems.
\end{abstract}

Keywords: structural vulnerability; cold-formed steel shear wall; concrete-filled cold-formed steel tube; failure mechanism

\section{Introduction}

In recent decades, cold-formed steel (CFS) shear wall systems are considered to be one of the most feasible approaches for constructing residential and commercial low-rise and mid-rise buildings because this system has numerous benefits such as environmental-friendly and recyclable materials, lightweightness, high performance, cost-effectiveness, dimensional modularity and stability, and convenience for construction. CFS products have the highest overall recycling rate of $66 \%$ [1]. A series of studies have been performed on CFS shear walls [2], including board-sheathed CFS shear walls [3-5], steel-sheathed CFS shear walls [6], and CFS shear walls sheathed with double-layer wallboards [7]. These shear wall systems were usually used in low-rise buildings, however, such systems are inadequate for mid-rise buildings, because only wallboards supply lateral-resistance. Therefore, researchers have looked for more methods of strengthening such shear walls, such as adding 
steel straps and trusses to the wall [8]. Strap-braced CFS walls were proposed by Mirzaei et al. [9] to verify the seismic design provisions of the American Iron and Steel Institute (AISI). A series of cyclic tests on CFS diagonal strap-braced stud walls was performed by Fiorino et al. [10]. Knee-braced CFS shear walls were introduced by Zeynalian and Ronagh [11]; both cyclic tests and numerical analyses were performed to study their seismic performance. In addition, framed stud walls with strap braces and steel sheathing [12] and other composite walls were investigated sequentially.

However, the mechanical behavior of CFS shear walls was not changed though there were various improvements aforementioned in lateral stiffness and shearing strength. That is because the end studs of such shear walls are disconnected between the upper and lower stories, thus the lateral deformation of the walls is discontinuous between the layers. The walls would sway in a great lateral amplitude if/when subjected to earthquakes, which increases the collapse risk due to the P-delta effects. Therefore, in order to mitigate the disadvantageous influence of P-deta effects and enhance the collapse-resisting capacity of the shear walls, Wang and Ye [13] and Sabbagh et al. [14] suggested that both continuous end studs and rigid beam-column joints should be adopted to constitute a defensive frame, which would supply a second defense to resist seismic actions. This idea has been accepted by many researchers recently $[2,15,16]$. An X-shaped built-up CFS beam was used by Sabbagh et al. [14] to prevent local buckling occurring in the flange of the beam. In addition, the beams and the overhanging plate of the end studs were connected by bolts to achieve a rigid beam-column joint. Ye $[13,17]$ proposed a reinforced cold-formed steel (RCFS) shear wall system, in which a concrete-filled CFS tube was used as an end stud to prevent local buckling, and a reinforced block beam-column joint was presented in order to achieve a rigid connection. In addition, seismic performance tests on single-story [13], and two- and three-story [17] RCFS shear walls were performed by Ye et al. A series of tests were conducted by Tao et al. $[18,19]$ to investigate the mechanical behavior of concrete-filled CFS tubes, and the test results showed that such members exhibit better strength, stiffness, and ductility in comparison with the built-up CFS studs. Therefore, the RCFS shear wall provides the possibility of realizing multiple means of earthquake fortification for mid-rise CFS structure.

In recent years, the seismic failure mechanism of CFS shear walls has remained a hot topic. A series of cyclic tests was performed by Retamales et al. [20], and three typical damage states were defined as follows: $\mathrm{DS}_{1}$, superficial damage; $\mathrm{DS}_{2}$, local damage; and $\mathrm{DS}_{3}$, severe damage. The definitions, which were concluded by considering the effects of connection type, wall height, framing thickness, and intersection details, were used as a guidance for a performance-based design of CFS structures. Shaking table tests of CFS shear walls were conducted by Wang et al. [21] and Jenkins et al. [22], in which inter-story drift ratio was used to represent the failure evolution process of the structures. Additionally, shaking table tests were performed on low-rise CFS shear walls [23-25]; the test results revealed that sheathing failure along with the end studs losing their axial load-bearing capacities in succession were the typical failure modes of those structures. The failure mechanism investigations were performed mainly by cyclic testing of CFS shear walls and shaking table test of CFS structures, and macro-indexes (such as inter-story drift and force) were used to reveal the failure process by analyzing the typical failure modes of the structures. However, those studies are still lack s supporting theory, and the macro-indexes cannot reveal the failure mechanism radically.

With respect to structural vulnerability, the inherent weakness of a structure is identified by analyzing the relationship between its topology form and connectivity, and in doing so, the failure mechanism will be further revealed. The vulnerability of a structure was defined as the ratio of the failure consequence to its relative damage demand [26,27], and the internal structural form and connectivity were seen as the reasons of the vulnerability of the structure. Possible failure scenarios of structures were identified by the process of clustering and unzipping [28,29], and the inherent weakness of a structure was detected through analyzing those different failure scenarios; this theory was then extended to 3D structures. Pinto et al. [30] performed a vulnerability analysis on two traditional Portuguese roof timber structures, identified the vulnerability indexes for various failure scenarios, and verified the applicability of this analysis method by comparison with actual failure 
scenarios. A series of vulnerability analyses was performed on three single-layer reticulated K6 domes by Ye et al. [31-33], and the collapse modes of three shaking table test models agreed well with the predicted results with respect to the maximum vulnerability indexes, confirming the validity of the theory in revealing the collapse mechanism for 3D space structures.

Therefore, a method exists to determine the seismic failure mechanism of the traditional and RCFS shear wall systems based on structural vulnerability analyses. In this paper, such a method is improved by considering both the fracture behavior of wallboards and the hinge-forming behavior of columns. Structural vulnerability analyses on three two-story CFS shear walls were performed to verify the practicability and validity of the proposed method by comparing the analysis results and test results. Structural robustness of the traditional and RCFS shear wall systems was quantitatively represented by the vulnerability indexes. In addition, "strong frame weak wallboard" and "strong column weak beam" were proposed as the conceptional rules for the seismic design of RCFS shear wall systems on the basis of the vulnerability results.

\section{RCFS Shear Wall System}

The RCFS shear wall system investigated in this paper is proposed by Ye et al. [17]; in comparison with the traditional CFS shear wall system shown in Figure 1a, it has the following improvements: (1) a concrete-filled CFS tube (CFRST) column was used as an end stud which was continuously constructed along the vertical direction, and the cross-section and constructed diagram are presented in Figure 1b; (2) a reinforced block beam-column joint was used to realize rigid connection, and the constructed diagram is shown in Figure $1 b$.

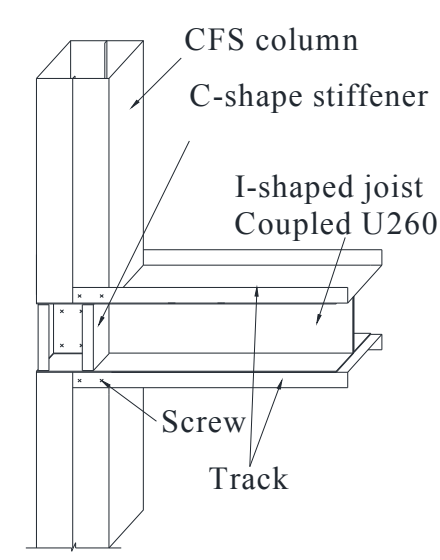

(a)

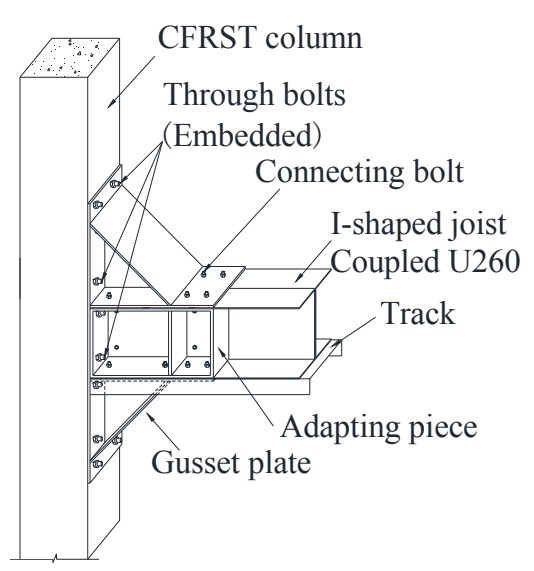

(b)

Figure 1. Beam-column joint diagram of the shear wall systems. (a) Traditional type; (b) reinforced type. CFS, cold-formed steel. CFRST, concrete-filled CFS tube. Reproduced with permission from [17], Elsevier, 2016.

Figure 2 shows the seismic deformation diagrams of two-story traditional and RCFS shear wall systems. For the traditional one, due to the separation between the upper and lower stories at end studs, the deformation of the shear walls combines relative uplifting and rigid rotation subjected to the overturning moment caused by earthquakes, as shown in Figure 2a. Thus, the deformation of the traditional shear wall system includes shearing deformation, bending deformation, and rigid rotation. For the RCFS shear wall system, due to the rigid column bases and beam-column joints, the relative uplifting and rigid rotation are avoided, thus their deformation is dominated by shearing deformation, as shown in Figure 2b. 


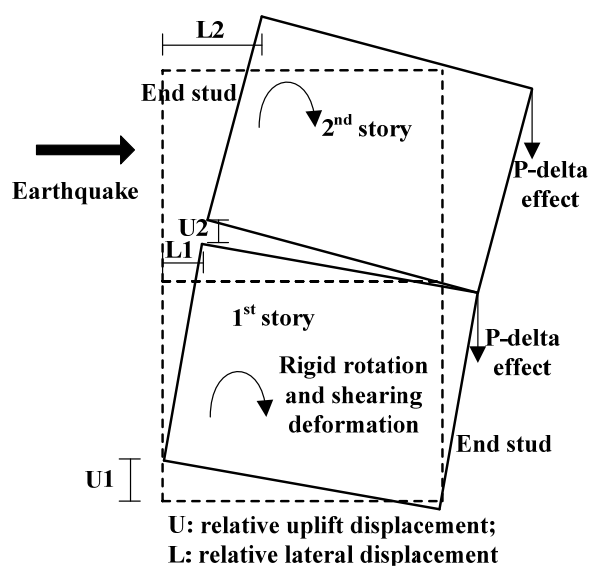

(a)

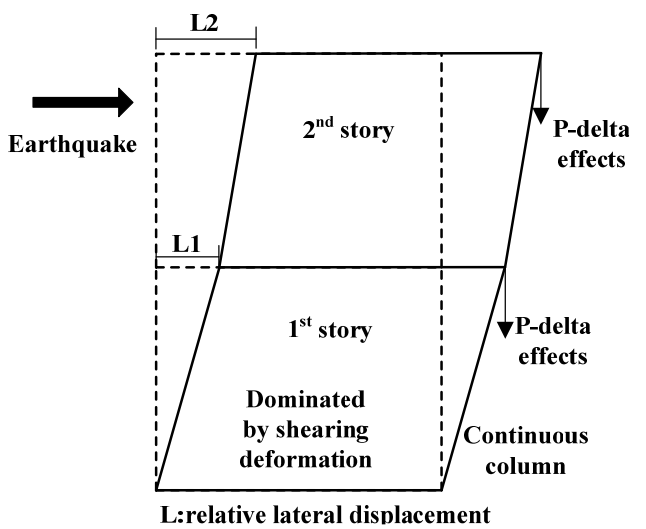

(b)

Figure 2. Deformation diagram of CFS shear wall systems under earthquakes (a two-story shear wall system is chosen as an example). (a) Traditional type. Reproduced with permission from [6], American Society of Civil Engineers, 2013; (b) reinforced type.

Consequently, the lateral deformation of the traditional type (Figure 2a) is larger than that of the reinforced one (Figure 2b) under the conditions of the same materials and loads. The P-delta effect on the traditional CFS shear wall system is more disadvantageous than the RCFS shear wall system, which was resulting in the traditional CFS shear wall system exhibiting a larger collapse risk.

\section{Structural Vulnerability Theory}

Structural vulnerability theory [26-29] is a theory focused on the quality of the structural form, and is able to identify the weakest part of a structure. This theory evaluates the quality of structural form through the value of well-formedness, and two main processes are contained in structural vulnerability analysis, including the clustering process, in which the hierarchical relationship model of the structure can be established according to clustering criteria, and the unzipping process, in which the possible failure modes of the structure can be identified based on unzipping rules.

\subsection{Well-Formedness}

Well-formedness is defined as an assessment indicator for the connection of each joint. According to previous studies [26,27], the well-formedness of joint $i$ is calculated as:

$$
q_{i}=\operatorname{det}\left(D_{i i}\right)=\lambda_{1} \times \lambda_{2} \times \lambda_{3}
$$

where principal stiffness coefficients $\lambda_{1}, \lambda_{2}$, and $\lambda_{3}$ reflect the stiffness along the direction defined by the corresponding eigenvectors. The values of principal stiffness coefficients are relative to the connection type of the joint. As for pinned joints, $\lambda_{1}$ and $\lambda_{2}$ are the translational stiffness coefficients, while $\lambda_{3}$ is the rotational stiffness whose value is vacant.

For a building with $n$ joints, the well-formedness of the structure is defined as an average value of all the joints:

$$
Q(n)=\sum_{i=1}^{n} \frac{q_{i}}{n}
$$

\subsection{Clustering Process}

The clustering process consists of identifying primitive structural clusters made up of members at the lower level of a structure. The clustering process can be divided into three stages [26]: initial clustering stage, second clustering stage, and reference clustering stage. 
Five typical clustering criteria are proposed in structural vulnerability theory [26-29]:

1. Maximum well-formedness $(Q)$;

2. Highest minimum damage demand $\left(D_{\min }\right)$;

3. Maximum nodal connectivity $(N)$;

4. Maximum distance from the reference $\left(D_{\text {is }}\right)$;

5. Free choice $\left(F_{\mathrm{c}}\right)$.

\subsection{Unzipping Process}

The first step of the unzipping process starts at the top of the hierarchical model. Then a new hierarchy model is built based on the remaining components, and the new hierarchy model is unzipped in the same way. This process continues until the structure or part of it becomes a mechanism (total collapse), and the sequence of damage events is a typical failure scenario. Eight unzipping criteria are proposed in structural vulnerability theory [27]:

1. The subcluster is not a reference cluster, $N_{\mathrm{R}}$;

2. The subcluster forms a ring with the reference cluster, $F_{\mathrm{R}}$;

3. The subcluster connects directly to the reference cluster, but does not form a ring with the reference cluster, $C_{\mathrm{D}}$;

4. The subcluster is a leaf cluster rather than a branch cluster, $L$;

5. The subcluster has the least well-formedness, $S_{\mathrm{Q}}$;

6. The subcluster has the smallest minimum damage demand, $S_{\mathrm{D}}$;

7. The subcluster was clustered most recently, $C_{\mathrm{L}}$;

8. If none of the above criteria apply, then a free choice is made, $F_{\mathrm{C}}$.

\subsection{Vulnerability Index}

To evaluate the damage consequence and the required damage demand of the various types of failure modes for the structure, the following evaluating indexes are defined in structural vulnerability theory [26-29]:

(1) Separateness $(\gamma)$ : it is measured by the ratio of the loss of well-formedness to the original well-formedness of the structure, which evaluates the damage consequence.

$$
\gamma=\frac{Q(S)-Q(S \prime)}{Q(S)}
$$

where $Q(S)$ and $Q\left(S^{\prime}\right)$ are the well-formedness of the original structure and residual structure, respectively. If no damage has occurred on the structure, the separateness is 0 ; however, if the structure is totally damaged, the value of $\gamma$ equals 1 .

(2) Relative damage demand $\left(D_{r}\right)$ : it is calculated by the ratio of the damage demand for the corresponding failure mode to the total damage demand of the structure.

$$
D_{r}=\frac{D}{D_{\max }}
$$

where $D$ is the total damage demand for the members in the structure corresponding to a particular failure mode; $D_{\max }$ is the total damage demand of all the members in the structure.

(3) Vulnerability index: it is an index to value the structural vulnerability, which is calculated by the ratio of the separateness to the relative damage demand.

$$
\phi=\frac{\gamma}{D_{r}}
$$




\section{Structural Vulnerability Analyses on Two-Story CFS Shear Wall Systems}

To perform the structural vulnerability analyses on a CFS shear wall system, three single-bay full-scale two-story CFS shear wall test models were selected. Figure 3 shows a photograph of cyclic loading tests on these three test models that were conducted by the authors in previous research. The specimens include traditional shear wall system $W_{1}$ and RCFS shear wall systems $W_{2}$ and $W_{2-1}$, which differ in the end stud type and sheathing board, as shown in Figures 4 and 5, and Table 1. An I-shaped built-up CFS member was used as the beam, and the steel of all the CFS members was Grade $345 \mathrm{MPa}$.

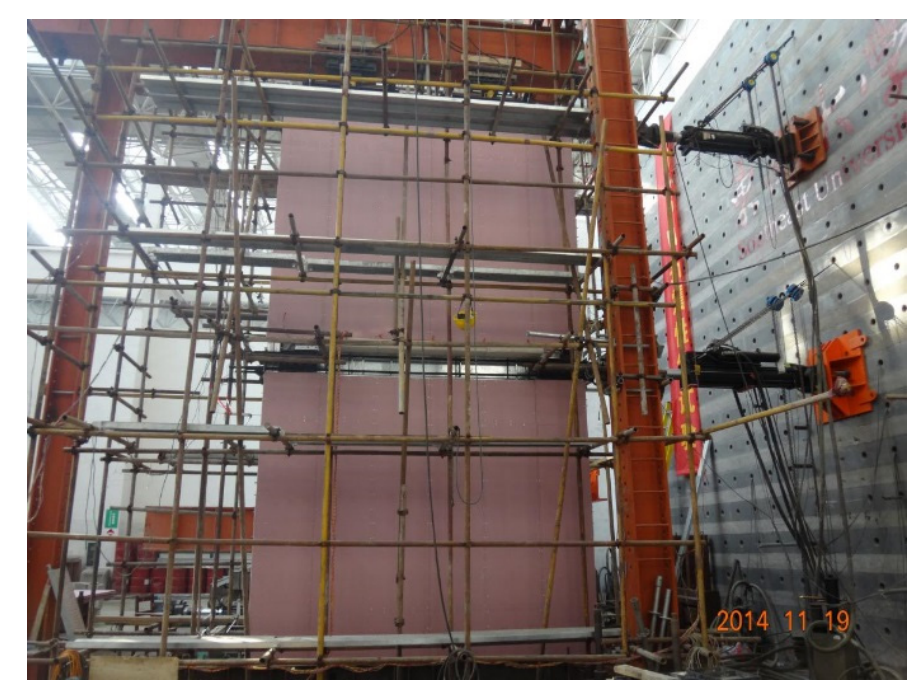

Figure 3. Cyclic loading tests of CFS shear wall systems.

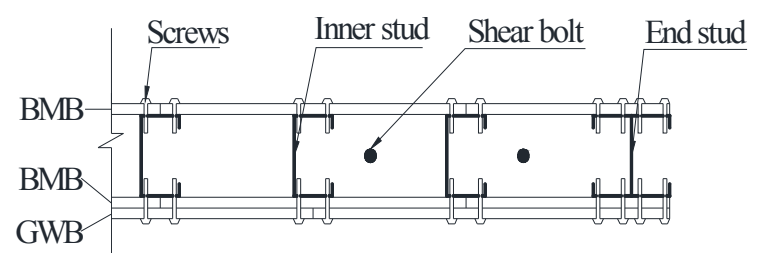

(a)

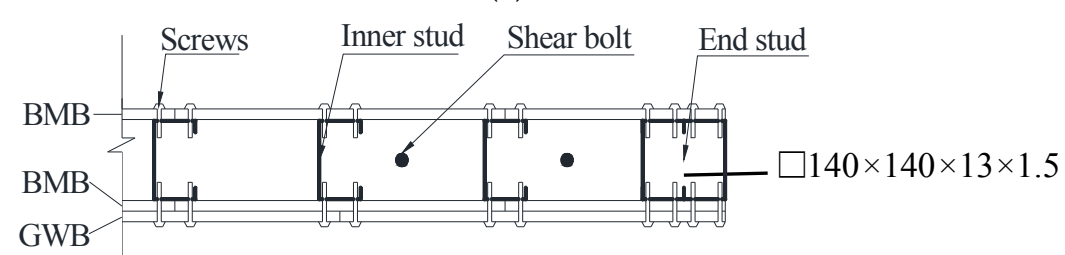

(b)

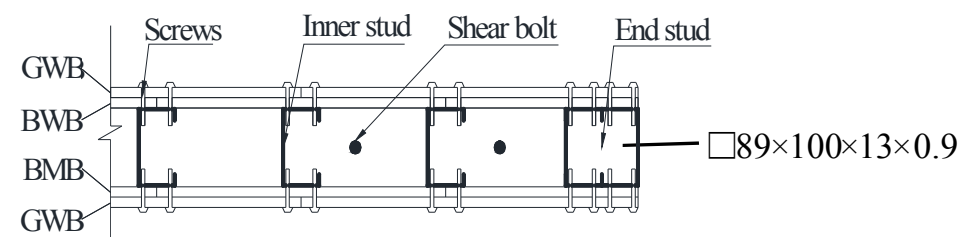

(c)

Figure 4. Section details of the specimens. (a) Traditional shear wall system $W_{1}$; (b) reinforced cold-formed steel (RCFS) shear wall system $W_{2}$; (c) RCFS shear wall system $W_{2-1}$. 


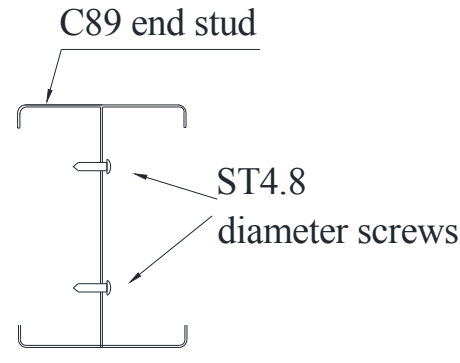

(a)
Fine aggregate concrete

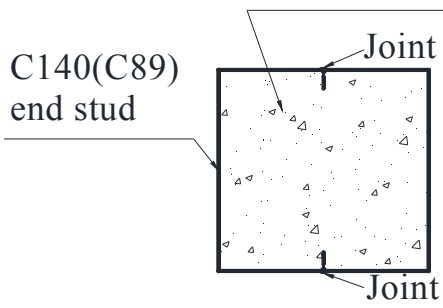

(b)

Figure 5. Cross-section details of the specimens' end studs. (a) Traditional shear wall system $W_{1}$;

(b) RCFS shear wall system $W_{2}\left(W_{2-1}\right)$.

According to the actual configuration of the traditional and RCFS shear wall systems, the simplified models are shown in Figure 6. The sheathing boards were equivalent to diagonal members based on a Japanese standard (JISF 2002) [34], in which an equivalent-bracing model is used to evaluate the lateral stiffness of CFS shear walls. Meanwhile, Dubina [35,36] and Ye et al. $[13,17]$ indicated that the interior studs had no obvious contribution to the lateral stiffness of the wall and only provided out-of-plane constraints for the wallboards. Therefore, subjected to the horizontal loads, those studs were equivalent to diagonal members along with the wallboards. On the basis of the test results $[13,17]$, the axial stiffness $E A$ of the equivalent bracing (see Figure 6) was determined. The section parameters of the frame members are listed in Table 1.

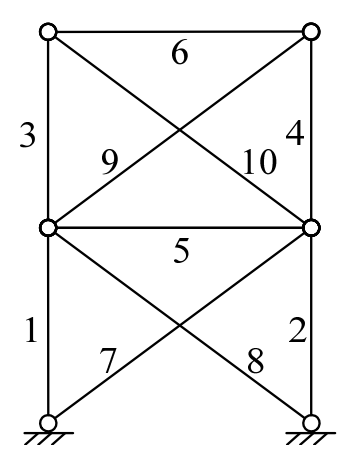

(a)

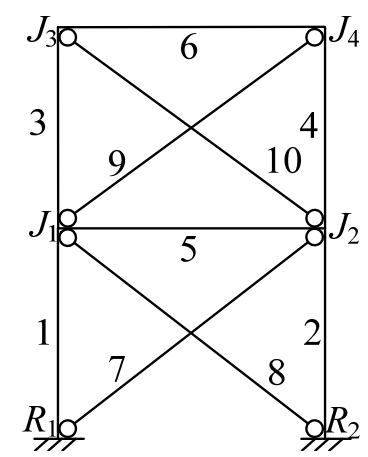

(b)

Figure 6. Simplified models of the specimens. (a) Traditional shear wall system $W_{1}$; (b) RCFS shear wall system $W_{2}\left(W_{2-1}\right)$. 
Table 1. Section parameters of the specimens.

\begin{tabular}{|c|c|c|c|c|}
\hline Member & Section Type (mm) & Length (m) & $E A(\mathrm{~N})$ & $E I\left(\mathrm{~N} \cdot \mathrm{m}^{2}\right)$ \\
\hline End stud & $\begin{array}{l}\text { Coupled C89 × } 100 \times 0.9^{\mathrm{a}}\left(W_{1}\right) \\
\square 140 \times 140 \times 13 \times 1.5^{\mathrm{b}}\left(W_{2}\right) \\
\square 89 \times 100 \times 13 \times 0.9^{\mathrm{c}}\left(W_{2-1}\right)\end{array}$ & All are 3.0 & $\begin{array}{l}7.830 \times 10^{7} \\
2.467 \times 10^{8} \\
9.952 \times 10^{7}\end{array}$ & $\begin{array}{l}5.254 \times 10^{4} \\
3.287 \times 10^{5} \\
1.260 \times 10^{5}\end{array}$ \\
\hline Beam & Coupled C89 $\times 100 \times 0.9^{d}$ & 3.6 & $7.830 \times 10^{7}$ & $1.031 \times 10^{5}$ \\
\hline $\begin{array}{l}\text { Sheathing } \\
\text { (equivalent } \\
\text { bracing) }\end{array}$ & $\begin{array}{l}12 \mathrm{~mm} \text { BMB for the base layer, } \\
12 \mathrm{~mm} \text { BMB along with } 12 \mathrm{~mm} \text { GWB } \\
\text { for the face layer }\left(W_{1} \text { and } W_{2}\right) \\
12 \mathrm{~mm} \text { BMB along with } 12 \mathrm{~mm} \text { GWB for } \\
\text { both the base and the face layers }\left(W_{2-1}\right)\end{array}$ & All are 4.686 & $\begin{array}{l}6.208 \times 10^{6} \\
9.531 \times 10^{6}\end{array}$ & \\
\hline Track & $\begin{array}{l}\mathrm{U} 91 \times 50 \times 0.9\left(W_{1} \text { and } W_{2-1}\right) \\
\mathrm{U} 142 \times 50 \times 1.5\left(W_{2}\right)\end{array}$ & $\begin{array}{l}\text { Ignoring their } \\
\text { only the conn }\end{array}$ & $\begin{array}{l}\text { ibution to th } \\
\text { function wa }\end{array}$ & $\begin{array}{l}\text { bal stiffness, } \\
\text { nsidered. }\end{array}$ \\
\hline
\end{tabular}

Note: ${ }^{a, d}$ Coupled C-section (see Figure $5 a$ ); ${ }^{b, c}$ Concrete-filled rectangular steel tube columns (see Figure $5 b$ ); the values of the elastic modulus of steel $\left(E_{\mathrm{S}}\right)$ and concrete $\left(E_{\mathrm{c}}\right)$ are $2.06 \times 10^{5} \mathrm{MPa}$ and $8.61 \times 10^{3} \mathrm{MPa}$, respectively. $\mathrm{BMB}$ and GWB represent Bolivian magnesium board and gypsum wall board, respectively.

\subsection{Traditional Shear Wall System $W_{1}$}

For a traditional shear wall, the construction of a beam-column joint is depicted in Figure 1a, and the deformation diagram is shown in Figure 2a. There are not only ductile CFS members but also brittle sheathing boards in the traditional shear wall system $W_{1}$. According to the clustering criteria of the structural vulnerability theory (obtained in Section 3.2), the hierarchical model of the shear wall system is established in Figure 7. In addition, possible failure modes (FM) of the shear wall system were obtained based on the unzipping criteria, as described in Section 3.3, and the unzipping process was depicted in Figure 7. Only the collapse modes are summarized in Table 2 and Figure 8.

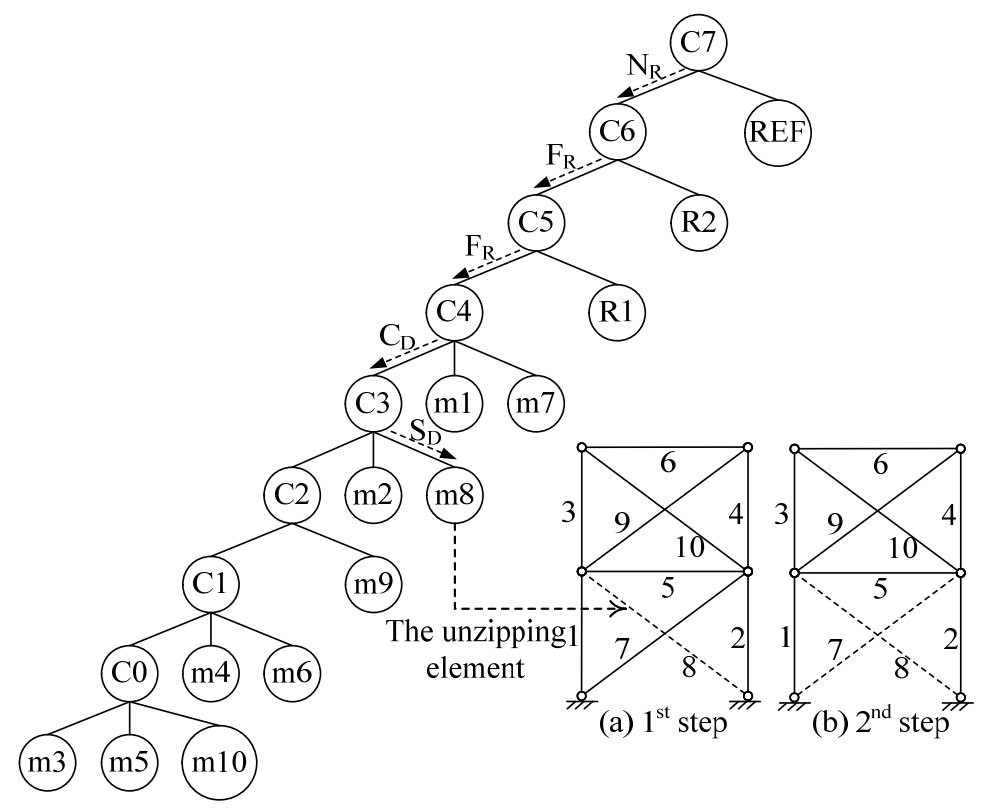

Figure 7. Hierarchical model and unzipping process of the traditional shear wall system $W_{1}$. 
Table 2. Vulnerability results of the traditional shear wall system $W_{1}$.

\begin{tabular}{ccccc}
\hline Collapse Mode & Failure Mode & Separateness $\gamma$ & $\begin{array}{c}\text { Relative Damage } \\
\text { Demand } D_{\mathbf{r}}\end{array}$ & $\begin{array}{c}\text { Vulnerability } \\
\text { Index } \boldsymbol{\phi}\end{array}$ \\
\hline Total collapse & Figure 8a & $\mathbf{1 . 0}$ & $\mathbf{0 . 1 5 8 1}$ & $\mathbf{6 . 3 2 5}$ \\
mode & Figure 8b & 1.0 & 0.1949 & 5.131 \\
& Figure 8c & 1.0 & 0.2614 & 3.826 \\
\hline $\begin{array}{c}\text { Local collapse } \\
\text { mode }\end{array}$ & Figure 8d & 0.355 & 0.1581 & 2.246 \\
\hline
\end{tabular}

Note: Bold indicates the same failure mode as in the test results.

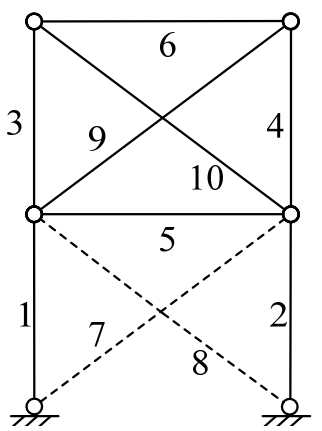

(a)

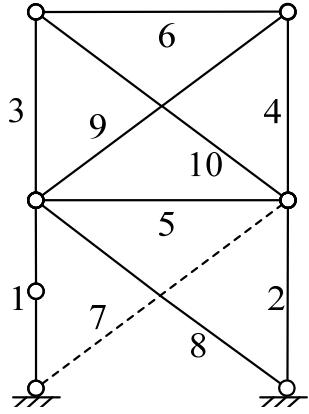

(b)

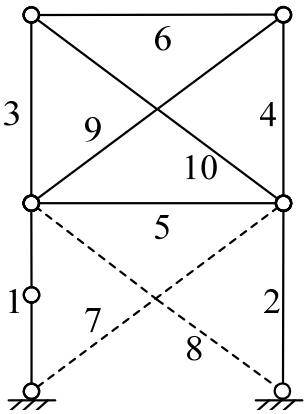

(c)

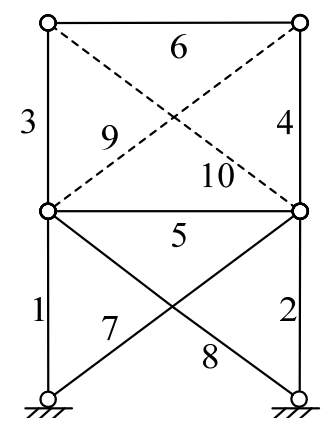

(d)

Figure 8. Primary collapse modes of specimen $W_{1}$. (a) FM1; (b) FM2; (c) FM3; (d) FM4.

Figure 9 shows the experimental behavior of specimen $W_{1}$. It appears that the total fracture of the sheathing boards occurred on one side of the specimen, and the boards were separated from the end studs. On the opposite side of the wall, the boards essentially were detached from the end studs due to the screws between the sheathings and end studs failing in shear or being pulled out of the boards. The connections between the end studs and their bases could not effectively restrain the studs' rotation. To protect the experimental equipment and ensure the security of the test, the loading procedure was terminated before the specimen attained its total collapse mode. However, the failure modes (Figure 9) reveal that when subjected to a horizontal load, the specimen has a total collapse tendency as a result of the separation between the boards and end studs. Such failure modes are resulting in a geometric variable system of the wall and further overturning collapse. This collapse tendency coincides with that shown in Figure 8a, meaning fractures of the equivalent braces. This type of collapse mode is the most incidental because of the highest vulnerability index amongst all collapse modes. Thus, the applicability of the structural vulnerability theory to the whole structure of such a traditional CFS shear wall system is verified.

It can be derived from Figure 8 and Table 2 that there is a notable difference in the vulnerability results between the lower and upper wall segments of the traditional CFS shear wall system, which means that a key wall element needs to be identified because the failure of the key element at different locations will induce various damage degrees to the structure. In the case of a severe earthquake, where the sheathings are the primary lateral load-bearing structural components, local collapse or even total collapse may take place as soon as they are damaged. That is because the structure has no redundant loading path if the sheathings are damaged. 


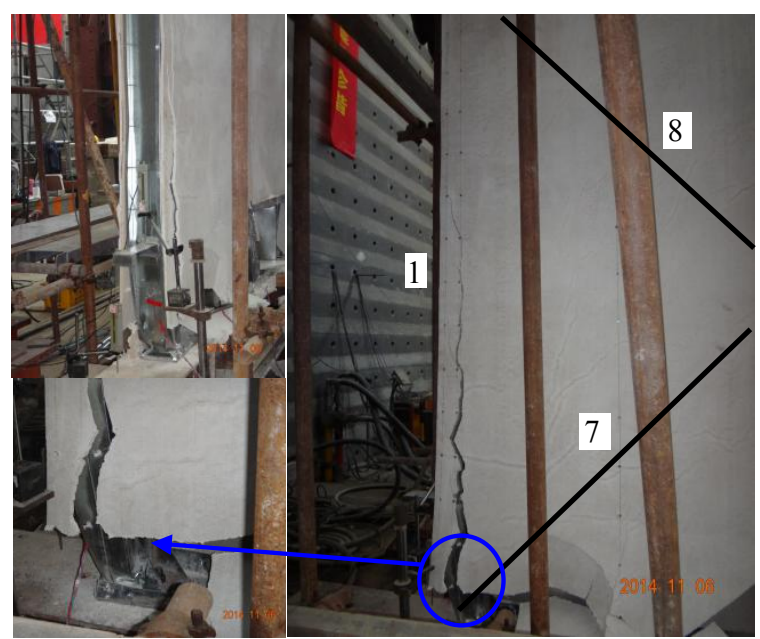

(a)

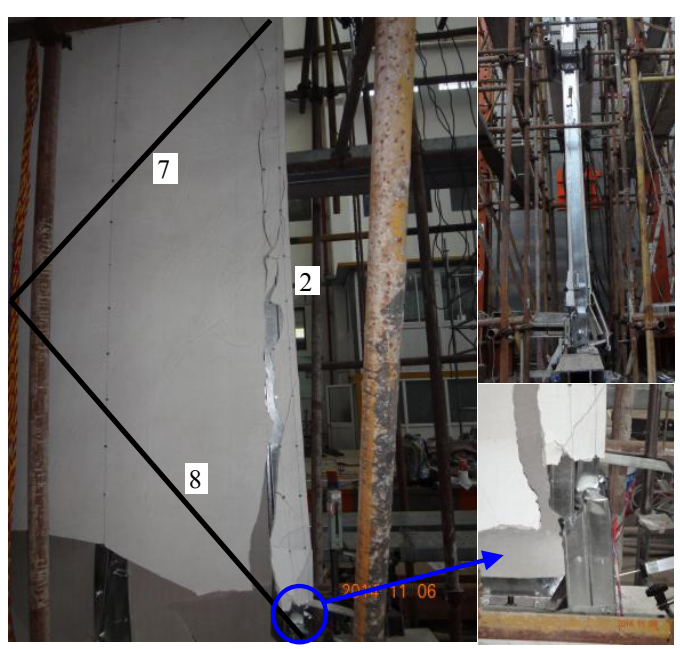

(b)

Figure 9. Experimental behavior of specimen $W_{1}$. (a) View on left side; (b) View on right side.

\subsection{RCFS Shear Wall System $W_{2}$}

Unlike the shear wall system $W_{1}$, both the beam-column joints and support joints in the RCFS shear wall system $W_{2}$ are rigid. According to the clustering and unzipping process defined in Sections 3.2 and 3.3, the hierarchical model and the corresponding unzipping process of specimen $W_{2}$ are illustrated in Figure 10, and the primary collapse modes are acquired, as summarized in Table 3.

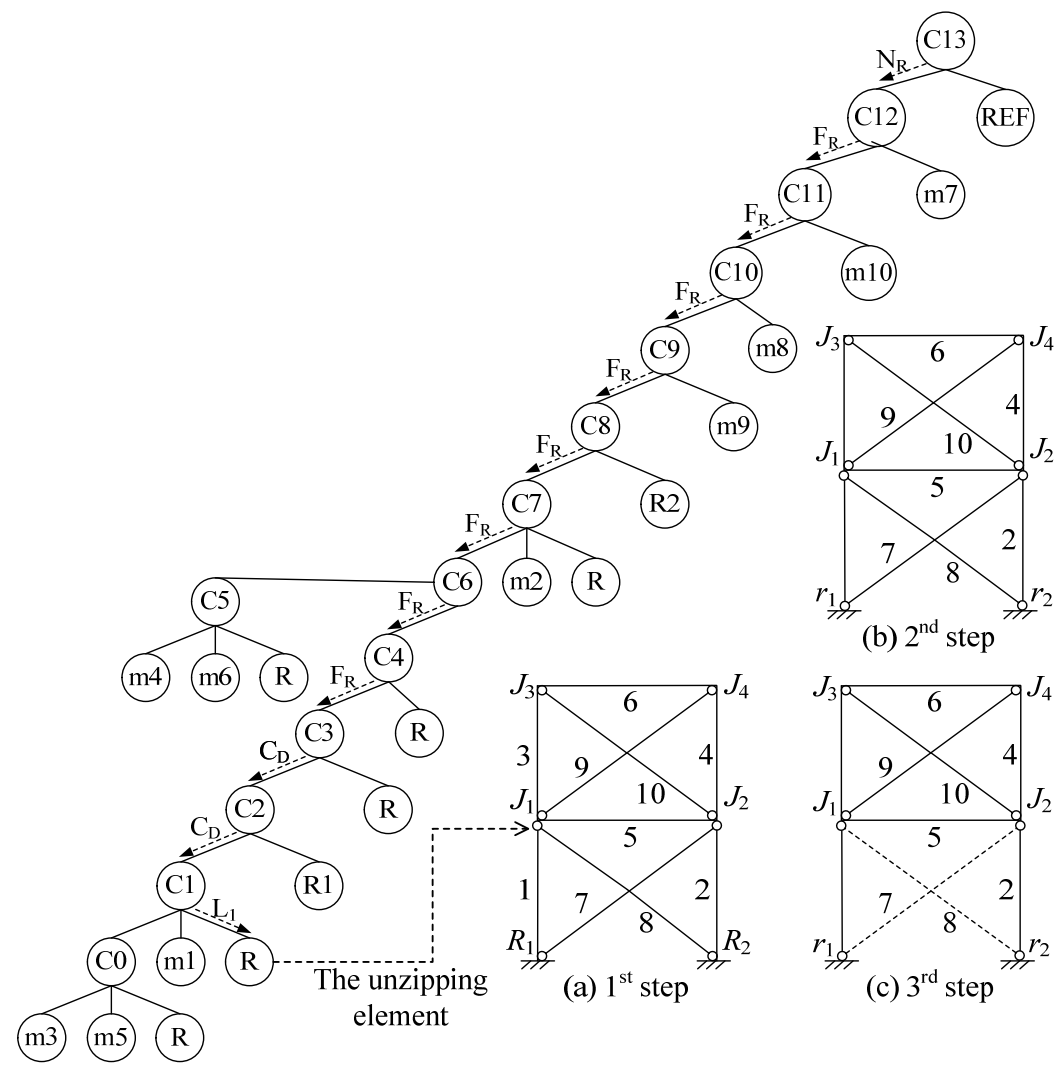

Figure 10. Hierarchical model and unzipping process of the RCFS shear wall system $W_{2}$. 
Table 3. Vulnerability results of the RCFS shear wall system $W_{2}$.

\begin{tabular}{ccccc}
\hline Collapse Mode & Failure Mode & Separateness $\gamma$ & $\begin{array}{c}\text { Relative Damage } \\
\text { Demand } \boldsymbol{D}_{\mathbf{r}}\end{array}$ & $\begin{array}{c}\text { Vulnerability } \\
\text { Index } \boldsymbol{\phi}\end{array}$ \\
\hline & Figure 11a & $\mathbf{1 . 0}$ & $\mathbf{0 . 2 0 8 8}$ & $\mathbf{4 . 7 8 9}$ \\
Total collapse & Figure 11b & 1.0 & 0.3666 & 2.728 \\
mode & Figure 11c & 1.0 & 0.3992 & 2.505 \\
& Figure 11d,e & 1.0 & 0.2345 & 4.264 \\
\hline $\begin{array}{c}\text { Local collapse } \\
\text { mode }\end{array}$ & Figure 11f (Expected mode) & 1.0 & 0.4535 & 2.205 \\
\hline
\end{tabular}

Note: Bold indicates the same failure mode as in the test results.

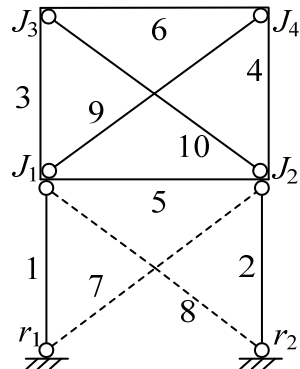

(a)

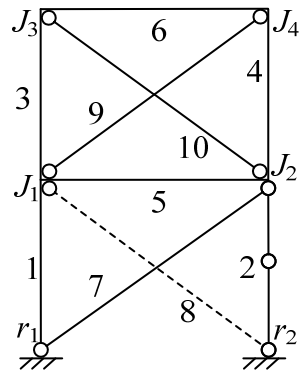

(e)

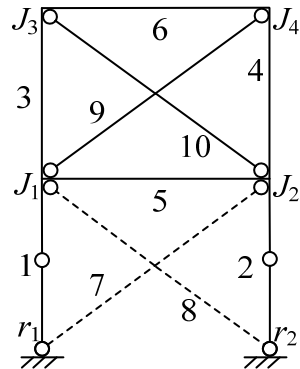

(b)

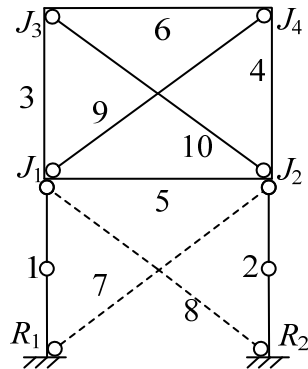

(c)

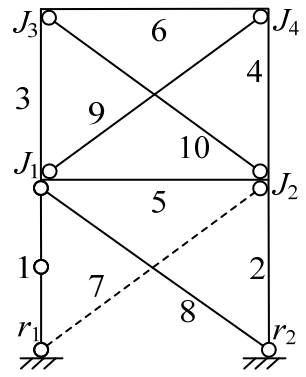

(d)

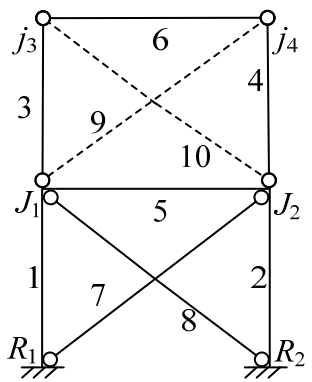

(g)

Figure 11. Primary collapse modes of specimen $W_{2}$. (a) FM1; (b) FM2; (c) FM3; (d) FM4; (e) FM5; (f) FM6; (g) FM7.

Figures 12 and 13 show the experimental behavior of specimen $W_{2}$. It was observed that the behavior of the sheathings on both sides was identical to that of specimen $W_{1}$. The rotation of the concrete-filled end stud bases cannot be effectively restrained because local buckling of the studs occurred in the vicinity of joints $R_{1}$ and $R_{2}$, as shown in Figure 13a,b. As such, the structure essentially loses or weakens its rigid connections with the foundation. Local buckling also appeared in the bottom end studs on top (at joints $J_{1}$ and $J_{2}$ ) (see Figure 13c,d). After the sheathing demolition, as shown in Figure 13e,f, the end studs basically lose their rigid connections with joints $J_{1}$ and $J_{2}$, because those joints can no longer effectively restrain the rotation of the studs. The loading procedure was terminated before the specimen reached its total collapse with the same purpose as that of specimen $W_{1}$. Nevertheless, as shown in Figures 12 and 13, the total collapse tendency and failure mechanism of the collapse of specimen $W_{2}$ are similar to those of specimen $W_{1}$, as a result of the rigid connection's loss on both ends of the bottom end studs in addition to the separation between the sheathings and end studs. The total collapse tendency is in line with that shown in Figure 11a, with fractures of the equivalent braces and transitions of both the support joints and joints $J_{1}$ and $J_{2}$ from rigid connections to pinned ones. This collapse mode is most likely to occur in severe earthquakes due to its highest 
vulnerability index, so the applicability of the structural vulnerability theory in RCFS shear wall systems is also verified.

In addition, the collapse mode shown in Figure $11 \mathrm{f}$ exhibits the minimum vulnerability index (Table 3), which means that such a collapse mode is the expected collapse mode of the RCFS shear wall system. Because the structure is collapsing with the maximum demands, it would therefore protect the structure under severe earthquakes to the greatest extent.

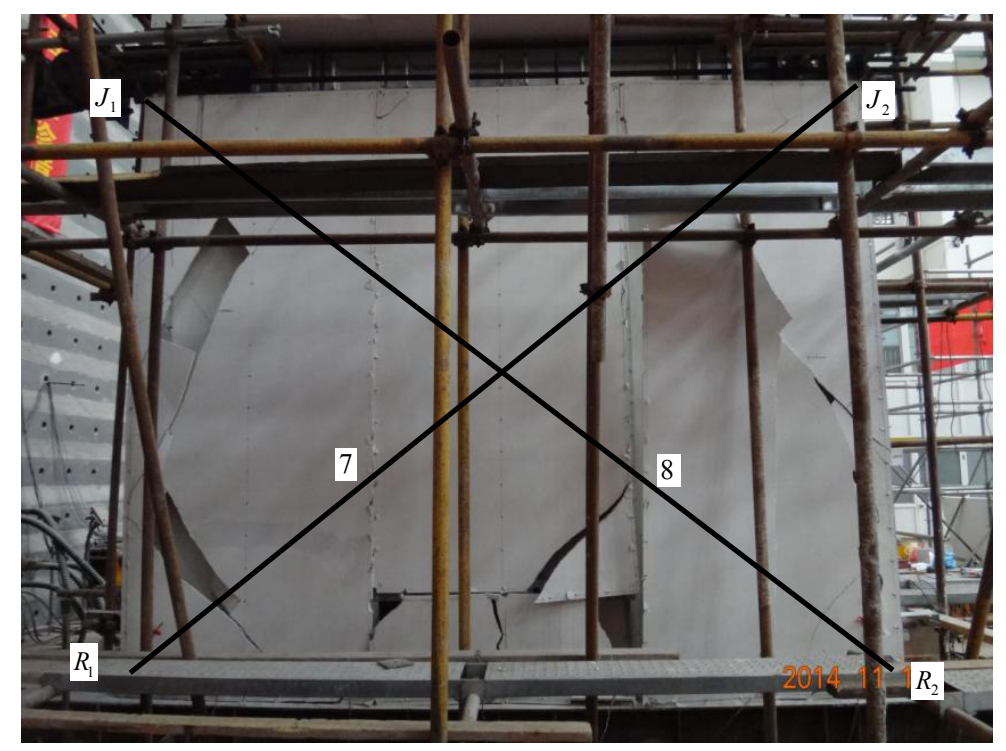

Figure 12. Experimental behavior of specimen $W_{2}$.

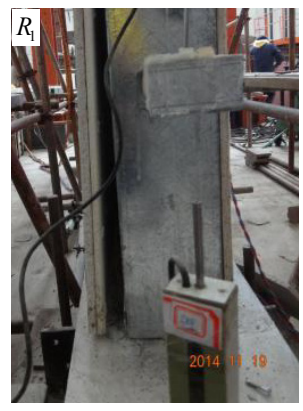

(a)

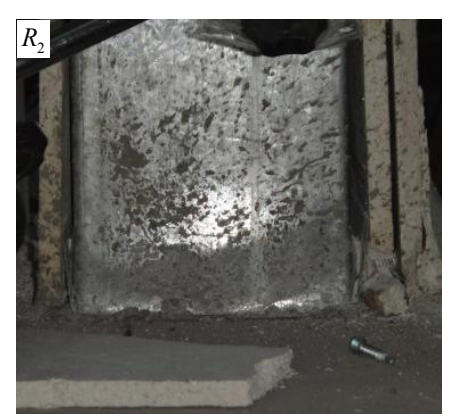

(b)

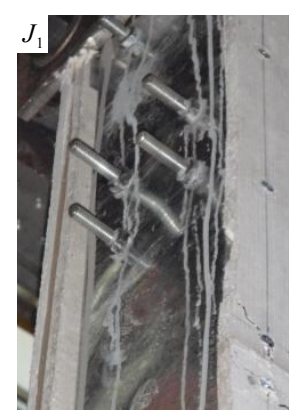

(c)

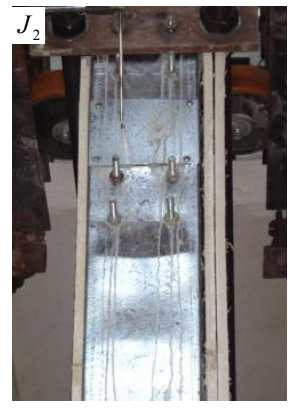

(d)

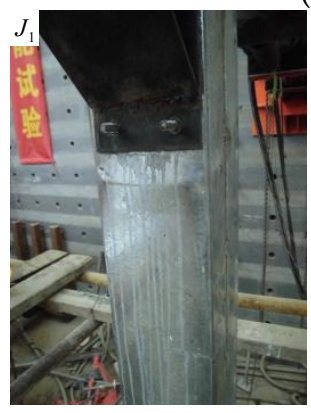

(e)

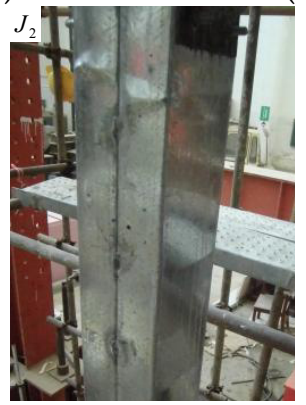

(f)

Figure 13. Buckling phenomenon of specimen $W_{2}(\mathbf{a})$ at joint $R_{1} ;(\mathbf{b})$ at joint $R_{2} ;(\mathbf{c})$ at joint $J_{1} ;(\mathbf{d})$ at joint $J_{2} ;$ (e) at joint $J_{1}$ (after sheathing demolition); (f) at joint $J_{2}$ (after sheathing demolition). 


\subsection{Effects of End Stud Type on the Collapse Modes of RCFS Shear Wall Systems}

RCFS shear wall systems suffer not only vertical loads but also bending moments because both the beam-column joints and support joints in the walls are rigid. The end studs thereby become a critical factor in the collapse resistance of the structure. The specimen $W_{2-1}$ is selected as a comparison with the specimen $W_{2}$, and the construction is presented in Figure $4 \mathrm{c}$ in detail. In comparison with $W_{2}$, the section and layout type of $W_{2-1}$ are changing from $\square 140 \times 140 \times 13 \times 1.5$ to $\square 89 \times 89 \times 13 \times 0.9$ and changing from the type depicted in Figure $4 \mathrm{~b}$ to the type illustrated in Figure $4 \mathrm{c}$, respectively.

The vulnerability results of specimen $W_{2-1}$ are listed in Table 4 , and the total collapse mode with the maximum vulnerability index is shown in Figure 11b. The specimen lost its axial loading-bearing capacity because compression buckling occurred in the lower parts of the end studs (see Figure 14a,b); moreover, joints $R_{1}$ and $R_{2}$ lost their restraints on the rotation of the end studs (see Figure $14 \mathrm{c}, \mathrm{d}$ ) due to buckling. The total collapse tendency of the specimen, which behaves as a result of failure occurring on an end stud, is in accordance with that shown in Figure 11a. Thus, the validity of the improved vulnerability analysis method is further verified.

Table 4. Vulnerability results of specimen $W_{2-1}$.

\begin{tabular}{ccccc}
\hline Collapse Mode & Failure Mode & Separateness $\gamma$ & $\begin{array}{c}\text { Relative Damage } \\
\text { Demand } D_{\mathbf{r}}\end{array}$ & $\begin{array}{c}\text { Vulnerability } \\
\text { Index } \boldsymbol{\phi}\end{array}$ \\
\hline Total collapse & Figure 11a & 1.0 & 0.3534 & 3.413 \\
mode & Figure 11b & $\mathbf{1 . 0}$ & $\mathbf{0 . 2 2 3 3}$ & $\mathbf{4 . 4 7 8}$ \\
\hline
\end{tabular}

Note: Bold indicates the same failure mode as in the test results.

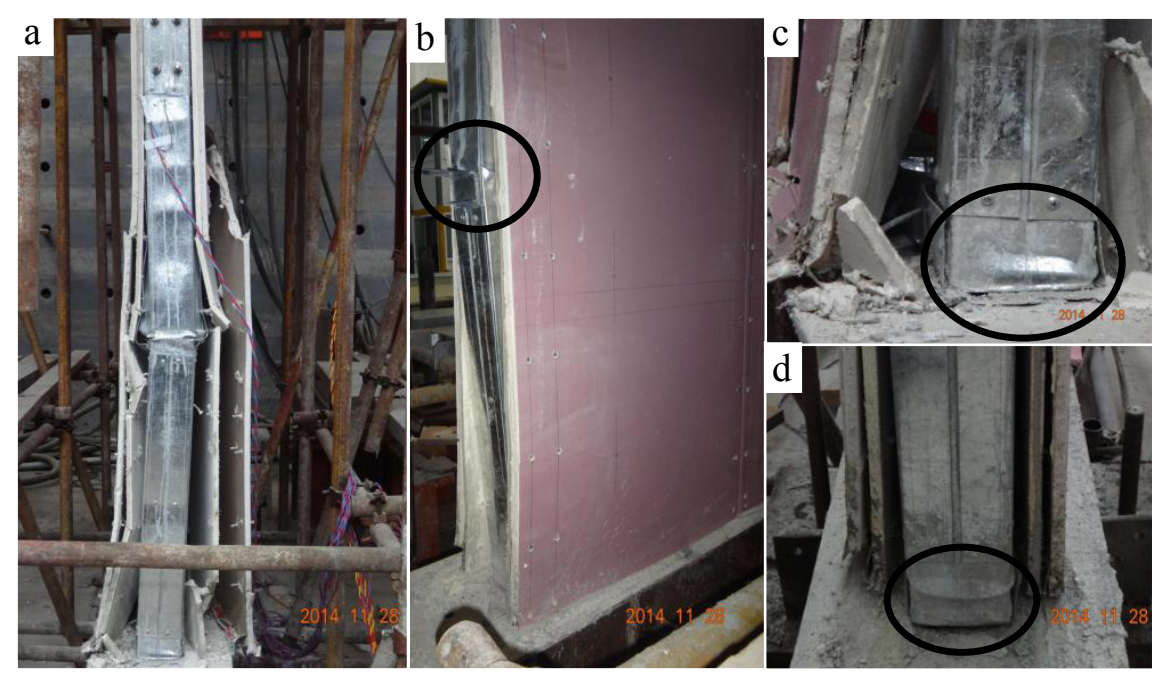

Figure 14. Buckling phenomena of specimen $W_{2-1}$ : (a) at the right end stud; (b) at the left end stud; (c) at joint $R_{2} ;(\mathrm{d})$ at joint $R_{1}$.

It can be concluded from Tables 3 and 4 that for specimen $W_{2}$ with the end studs' stiffness being large enough, the maximum vulnerability index of the total collapse modes is about $24.3 \%$ to $29.2 \%$ lower than that of the traditional shear wall system $W_{1}$, as such, the level of safety guarantee of the RCFS shear wall systems is higher. The reason for the safety is that the collapse resistance of the whole structure can be effectively enhanced due to the second defense line in addition to the sheathings, which is provided by the framework integrated by beams and end studs under rigid connection conditions. Moreover, the vulnerability index indicates that the RCFS shear wall system exhibits better structural robustness, which is because a structure with lower robustness has a higher vulnerability index $[28,29]$. On the other hand, in the case of end studs with insufficient stiffness, RCFS shear wall 
systems may have a total collapse mode caused by end stud failure, which is disadvantageous to the collapse resistance of the structure.

As in whole, the authors hold a point that the robust mid-rise RCFS shear wall system should be likely to fail in the mode shown in Figure $11 \mathrm{f}$ under severe earthquakes. Two reasons can support such a point: (1) the performance of structural members can be fully used, and two energy dissipating paths (wallboard is the first path and the beam-column joint is the second one) can be formed to delay the total collapse; (2) the vulnerability of such a failure mode is the lowest one, the disproportionate collapse degree of such a failure mode is the lowest one, thus the seismic robustness of the corresponding structure is the highest one, which is beneficial for the anti-seismic design for the RCFS shear wall system.

Therefore, conceptional rules of "strong frame, weak wallboard" and "strong column, weak beam" were proposed to guide the seismic design for the RCFS shear wall systems.

\section{Conclusions}

This study conducted vulnerability analyses on three two-story CFS shear wall systems based on forms. The effects of both the section type and size of end studs on the failure modes of CFS shear wall systems were discussed. The conclusions are summarized as follows:

1. Compared with test results, the vulnerability analysis method accurately predicted the damage locations and collapse modes of the traditional and RCFS shear wall systems. It was indicated that the structural vulnerability method can effectively identify the weakness of the shear walls, thus the proposed method can be used to reveal the seismic failure mechanism of such shear walls.

2. For a two-story traditional CFS shear wall system, sheathing wallboards play a decisive role in the lateral resistance, and the structure would totally lose its lateral load-bearing capacity once the sheathing wallboards failed. For a RCFS shear wall system with end studs having sufficient stiffness, the collapse resistance of the whole structure can be effectively enhanced by a second form of defense, which is provided by the framework integrated by beams and end studs under rigid connection conditions together with their rigid connections to the foundation. In the case of end studs with insufficient stiffness, the RCFS shear wall system may have a total collapse mode caused by end stud failure, which is disadvantageous to the collapse resistance of the structure.

3. According to the vulnerability indexes, it was shown that the RCFS shear wall system exhibits better structural robustness in comparison with the traditional one. In addition, to target the expected failure mode (this failure mode exhibits the lowest vulnerability in total collapse modes) presented in Figure 11f subjected to severe earthquakes, conceptional rules of "strong frame, weak wallboard" and "strong column, weak beam" were proposed for the seismic design of mid-rise RCFS structures.

Acknowledgments: This research is sponsored by the National Key Program Foundation of China (51538002) and the Priority Academic Program Development of Jiangsu Higher Education Institutions, Scientific Innovation Research Foundation of Jiangsu, China (KYLX15_0090) and a Project Funded by the Priority Academic Program Development of Jiangsu Higher Education Institutions (CE02-2-32).

Author Contributions: Jihong Ye contributed to the conception of the study and modified the manuscript; Liqiang Jiang performed the analyses and wrote the manuscript; Xingxing Wang conducted the tests.

Conflicts of Interest: The authors declare no conflict of interest.

\section{References}

1. Bae, S.W.; LaBoube, R.A.; Belarbi, A.; Ayoub, A. Progressive collapse of cold-formed steel framed structures. Thin-Walled Struct. 2008, 46, 706-719. [CrossRef]

2. Hancock, G.J. Cold-formed steel structures: Research review 2013-2014. Adv. Struct. Eng. 2016, 19, 393-408. [CrossRef]

3. Liu, P.; Peterman, K.D.; Schafer, B.W. Impact of construction details on OSB-sheathed cold-formed steel framed shear walls. J. Constr. Steel Res. 2014, 101, 114-123. [CrossRef] 
4. Zeynalian, M.; Ronagh, H.R. Seismic performance of cold formed steel walls sheathed by fiber-cement board panels. J. Constr. Steel Res. 2015, 107, 1-11. [CrossRef]

5. Mowrtage, W. Cyclic lateral load behavior of CFS walls sheathed with different materials. Thin-Walled Struct. 2015, 96, 328-336. [CrossRef]

6. Shamim, I.; DaBreo, J.; Rogers, C. Dynamic testing of single- and double-story steel-sheathed cold-formed steel-framed shear walls. J. Struct. Eng. 2013, 139, 807-817. [CrossRef]

7. Ye, J.H.; Wang, X.X.; Jia, H.Y.; Zhao, M.Y. Cyclic performance of cold-formed steel shear walls sheathed with double-layer wallboards on both sides. Thin-Walled Struct. 2015, 92, 146-159. [CrossRef]

8. Dao, T.N.; Van de Lindt, J.W. Seismic performance of an innovative light-frame cold-formed steel frame for midrise construction. J. Struct. Eng. 2013, 139, 837-848. [CrossRef]

9. Mirzaei, A.; Sangree, R.H.; Velchev, K.; Comeau, G.; Balh, N.; Rogers, C.A.; Schafer, B.W. Seismic capacity-based design of narrow strap-braced cold-formed steel walls. J. Constr. Steel Res. 2015, 115, 81-91. [CrossRef]

10. Fiorino, L.; Luorio, O.; Macillo, V.; Terracciano, M.T.; Pali, T.; Landolfo, R. Seismic design method for CFS diagonal strap-braced stud walls: Experimental validation. J. Struct. Eng. 2016, 142, 04015154. [CrossRef]

11. Zeynalian, M.; Ronagh, H.R. An experimental investigation on the lateral behavior of knee-braced cold-formed steel shear walls. Thin-Walled Struct. 2012, 51, 64-75. [CrossRef]

12. Eom, T.S.; Ha, T.H.; Cho, B.H.; Kim, T.H. Cyclic loading tests on framed stud walls with strap braces and steel sheathing. J. Struct. Eng. 2015, 141, 04014173. [CrossRef]

13. Wang, X.X.; Ye, J.H. Reversed cyclic performance of cold-formed steel shear walls with reinforced end studs. J. Constr. Steel Res. 2015, 113, 28-42. [CrossRef]

14. Sabbagh, A.B.; Petkovski, M.; Pilakoutas, K.; Mirghaderi, R. Experimental work on cold-formed steel elements for earthquake resilient moment frame buildings. Eng. Struct. 2013, 42, 371-386. [CrossRef]

15. Qin, Y.; Chen, Z.H. Research on cold-formed steel connections: A state-of-the-art review. Steel Compos. Struct. 2016, 20, 21-41. [CrossRef]

16. Attari, N.K.A.; Alizadeh, S.; Hadidi, S. Investigation of CFS shear walls with one and two-sided steel sheathing. J. Constr. Steel Res. 2016, 122, 292-307. [CrossRef]

17. Wang, X.X.; Ye, J.H. Cyclic testing of two- and three-story CFS shear-walls with reinforced end studs. J. Constr. Steel Res. 2016, 121, 13-28. [CrossRef]

18. Tao, Z.; Han, L.H.; Wang, D.Y. Strength and ductility of stiffened thin-walled hollow steel structural stub columns filled with concrete. Thin-Walled Struct. 2008, 46, 1113-1128. [CrossRef]

19. Tao, Z.; Uy, B.; Han, L.H.; Wang, Z.B. Analysis and design of concrete-filled stiffened thin-walled steel tubular columns under axial compression. Thin-Walled Struct. 2009, 47, 1544-1556. [CrossRef]

20. Retamales, R.; Davies, R.; Mosqueda, G.; Filiatrault, A. Experimental seismic fragility of cold-formed steel framed gypsum partition walls. J. Struct. Eng. 2013, 139, 1285-1293. [CrossRef]

21. Wang, X.; Pantoli, E.; Hutchinson, T.C.; Restrepo, J.I.; Wood, R.L.; Hoehler, M.S.; Grzesik, P.; Sesma, F.H. Seismic performance of cold-formed steel wall systems in a full-scale building. J. Struct. Eng. 2015, 141, 04015014. [CrossRef]

22. Jenkins, C.; Soroushian, S.; Rahmanishamsi, E.; Maragakis, E.M. Experimental fragility analysis of cold-formed steel steel-framed partition wall systems. Thin-Walled Struct. 2016, 103, 115-127. [CrossRef]

23. Dubina, D. Structural analysis and design assisted by testing of cold-formed steel structures. Thin-Walled Struct. 2008, 46, 741-764. [CrossRef]

24. Peter, K.D.; Stehman, M.J.J.; Buonopane, S.G.; Nakata, R.L.M.; Schafer, B.W. Seismic performance of full-scale cold-formed steel buildings. In Proceedings of the 10th National Conference on Earthquake Engineering, Anchorage, AK, USA, 21-25 July 2014; EERI: Oakland, CA, USA, 2014.

25. Ozaki, F.; Kawai, Y.; Kanno, R.; Hanya, K. Damage-control systems using replaceable energy-dissipating steel fuses for cold-formed steel structures: Seismic behavior by shake table tests. J. Struct. Eng. 2013, 139, 787-795. [CrossRef]

26. Wu, X.; Blockley, D.I.; Woodman, N.J. Vulnerability analysis of structural systems part I: Rings and clusters. Civ. Eng. Syst. 1993, 10, 301-317. [CrossRef]

27. Wu, X.; Blockley, D.I.; Woodman, N.J. Vulnerability analysis of structural systems part II: Failure scenarios. Civ. Eng. Syst. 1993, 10, 319-333. [CrossRef] 
28. Agarwal, J.; Blockley, D.I.; Woodman, N.J. Vulnerability of 3-dimensional trusses. Struct. Saf. 2001, 23, 203-220. [CrossRef]

29. Agarwal, J.; Blockley, D.I.; Woodman, N.J. Vulnerability of structural system. Struct. Saf. 2003, 25, $263-286$. [CrossRef]

30. Murta, A.; Pinto, J.; Varum, H. Structural vulnerability of two traditional Portuguese timber structural systems. Eng. Fail. Anal. 2011, 18, 776-782. [CrossRef]

31. Ye, J.H.; Liu, W.Z.; Pan, R. Research on failure scenarios of domes based on form vulnerability. Sci. China Ser. E 2011, 54, 2834-2853. [CrossRef]

32. Zhu, N.H.; Ye, J.H. Structural vulnerability of a single-layer dome based on its form. J. Eng. Mech. 2014, 140, 112-127.

33. Liu, W.Z.; Ye, J.H. Collapse optimization for domes under earthquake using a genetic simulated annealing algorithm. J. Constr. Steel Res. 2014, 97, 59-68. [CrossRef]

34. Japan Iron and Steel Federation. Design Guide for Light Gauge Steel Buildings; Gihodo Shuppan Co. Ltd.: Tokyo, Japan, 2002.

35. Fülöp, L.A.; Dubina, D. Performance of wall-stud cold-formed shear panels under monotonic and cyclic loading: Part II: Numerical modelling and performance analysis. Thin-Walled Struct. 2004, 42, 339-349. [CrossRef]

36. Dubina, D. Behavior and performance of cold-formed steel-framed houses under seismic action. J. Constr. Steel Res. 2008, 64, 896-913. [CrossRef]

(C) 2017 by the authors; licensee MDPI, Basel, Switzerland. This article is an open access article distributed under the terms and conditions of the Creative Commons Attribution (CC BY) license (http:/ / creativecommons.org/licenses/by/4.0/). 